Pesq. Vet. Bras. 31(6):533-537, junho 2011

\title{
Resistência de bactérias isoladas de cães e gatos no Hospital Veterinário da Universidade Estadual de Londrina (2008-2009) ${ }^{1}$
}

\author{
Juliana B. Ishii ${ }^{2}$, Julio C. Freitas ${ }^{3}$ e Mônica V.B. Arias²*
}

\begin{abstract}
Ishii J.B., Freitas J.C. \& Arias M.V.B. 2011. [Resistance of bacteria isolated from dogs and cats at Veterinary Hospital of Universidade Estadual de Londrina (20082009).] Resistência de bactérias isoladas de cães e gatos no Hospital Veterinário da Universidade Estadual de Londrina (2008-2009). Pesquisa Veterinária Brasileira 31(6):533537. Departamento de Clínicas Veterinárias, Universidade Estadual de Londrina, Rodov. PR 445 Km 380, Campus Universitário, Londrina, PR 86051-990, Brazil. E-mail: vicky@uel.br

The bacterial resistance profile was studied in several disorders affecting dogs and cats treated at the Small Animals Surgical Clinics Division of Veterinary Hospital of Universidade Estadual de Londrina. The disorders etiologic agents recovered were identified and Staphylococcus spp. was the most prevalent (27.6\%), followed by Pseudomonas spp. (22.7\%) and Escherichia coli (16.6\%). In the antimicrobial susceptibility test using agar diffusion method, there was a high percentage of resistance to main antibiotics used to treat urinary tract infections, especially of Gram negative bacteria, which showed over $66 \%$ resistance to the antibiotics tested, except for norfloxacin. In wounds, only gentamicin and amikacin had resistance rates less than $50.0 \%$. In otological disorders, less resistance to norfloxacin and higher to neomycin, and lower rates of resistance in Gram positive bacteria were observed. In the orthopedic cases, the Gram positive bacteria showed higher resistance to ciprofloxacin, and in peritonitis was found $100 \%$ resistance to various antibiotics. This study emphasizes the importance of bacterial identification and implementation of testing of susceptibility to antibiotics to choose the appropriate antimicrobial agent in the treatment of the major diseases seen in this field of small animal veterinary medicine.
\end{abstract}

INDEX TERMS: Drug resistance, bacterial, microbial sensitivity tests, bacterial infections, antibiotics.

RESUMO.- Foi determinado o perfil de resistência de bactérias isoladas de diversas afecções em cães e gatos atendidos no Setor de Clinica Cirúrgica de Animais de Companhia do Hospital Veterinário da Universidade Estadual de Londrina. Houve maior frequência de Staphylococcus spp. (27,6\%), seguido por Pseudomonas spp. (22,7\%) e Escherichia coli $(16,6 \%)$. Na prova de sensibilidade antimicrobiana pelo método de difusão em ágar houve alta porcentagem de resistência das bactérias isoladas aos principais antibióticos usados no tratamento das infecções do trato urinário, principalmente das bactérias Gram negati-

\footnotetext{
${ }^{1}$ Recebido em 11 de agosto de 2010.

Aceito para publicação em 27 de dezembro de 2010.

2 Departamento de Clínicas Veterinárias, Universidade Estadual de Londrina (UEL), Campus Universitário, Rodovia Celso Garcia Cid, PR $445 \mathrm{Km} 380$, Londrina, PR 86051-990, Brasil. *Autor para correspondência: vicky@uel.br

${ }^{3}$ Departamento de Medicina Veterinária Preventiva, UEL, Campus Universitário, Londrina, PR.
}

vas que apresentaram resistência superior a $66 \%$ aos antibióticos testados, com exceção da norfloxacina. Nas bactérias isoladas de feridas, apenas a gentamicina e a amicacina demonstraram índices de resistência inferior a $50,0 \%$. Nas bactérias isoladas das afecções otológicas observou-se menor resistência à norfloxacina e maior à neomicina, sendo os menores índices de resistência observados nas bactérias Gram positivas. As bactérias Gram positivas apresentaram maior resistência à ciprofloxacina nos casos ortopédicos, e nas bactérias isoladas das peritonites houve $100 \%$ de resistência a diversos antibióticos. Este trabalho ressalta a importância da identificação bacteriana e a realização de antibiogramas para a escolha do agente antimicrobiano apropriado no tratamento das principais afecções atendidas na área de animais de companhia em medicina veterinária.

TERMOS DE INDEXAÇÃO: Resistência antimicrobiana, testes de suscetibilidade a antibióticos, infecções bacterianas, antibióticos. 


\section{INTRODUÇÃO}

A resistência aos antimicrobianos é uma das grandes preocupações para a comunidade médica e veterinária, pois é um problema complexo que envolve várias espécies bacterianas, seus mecanismos de resistência e transferência desta a outras bactérias (Guardabassi et al. 2004, Mendes et al. 2005). É causa conhecida de insucesso no tratamento de diversas afecções, principalmente quando se considera a emergência de bactérias multirresistentes (Sanchez et al. 2002).

O uso inadequado dos antimicrobianos no tratamento de infecções bacterianas em animais de companhia é alvo de diversas críticas, pois pode colaborar para o desenvolvimento de resistência bacteriana em animais e no homem (Pedersen et al. 2007, Pallo-Zimmerman et al. 2010). O aumento da resistência dificulta a seleção empírica dos antimicrobianos (Hoekstra \& Paultron 2002) e o seu monitoramento, que é responsabilidade dos Médicos Veterinários, é importante para a conservação da eficácia desses agentes (Clarke 2006).

As taxas de resistência aos antibióticos em animais de companhia se elevaram ao longo dos anos (Witte 1999, Werckethin et al. 2001), e esse aumento acompanhou a utilização mais frequente de antimicrobianos no tratamento de infecções nesses animais, pois cada vez mais os pacientes são tratados com antibióticos de amplo espectro sem a certeza da sua real necessidade, já que exames para a identificação bacteriana e a sua susceptibilidade antimicrobiana muitas vezes não são realizados (Guardabassi et al. 2004, Guardabassi et al. 2008).

Este trabalho teve como objetivo avaliar retrospectivamente o perfil de resistência antimicrobiana in vitro de isolados bacterianos de diversos processos infecciosos em 181 pacientes atendidos no Setor de Clínica Cirúrgica de Animais de Companhia do Hospital Veterinário da Universidade Estadual de Londrina (HV/UEL), entre janeiro de 2008 e dezembro de 2009, através da consulta aos prontuários clínicos e livros de registro do Laboratório de Microbiologia e Doenças Infecciosas do Departamento de Medicina Veterinária Preventiva da UEL/CCA.

\section{MATERIAL E MÉTODOS}

Foram avaliados 181 isolados bacterianos provenientes de diversas afecções de 147 cães e 34 gatos, machos e fêmeas, atendidos no Setor de Clínica Cirúrgica de Animais de Companhia do HV/UEL, entre janeiro de 2008 e dezembro de 2009. As amostras foram provenientes de pacientes atendidos na rotina hospitalar, submetidos ou não ao tratamento prévio com antimicrobianos. A avaliação dos isolados foi realizada no Laboratório de Microbiologia e Doenças Infecciosas do Departamento de Medicina Veterinária Preventiva da UEL/CCA.

As amostras dos casos otológicos, ortopédicos e de feridas foram coletadas por swab e duas amostras de feridas foram obtidas por biópsia realizada com punch. Nas afecções urinárias, as amostras de urina foram colhidas por cistocentese; quatro amostras, compostas por fragmentos da mucosa da bexiga foram obtidas durante o procedimento cirúrgico de cistotomia; uma amostra de urina foi coletada por sonda uretral. Nas peritonites as amostras foram obtidas por punção do líquido peritoneal.
Os meios de cultura utilizados foram caldo Muller Hinton ${ }^{4}$ e agar Muller Hinton ${ }^{4}$ sendo utilizadas de 3 a 5 colônias para semeadura. A concentração bacteriana foi correspondente a turbidez da escala 0,5 de Mc Farland e a espessura da camada de agar na placa $4 \mathrm{~mm}$. Para aferição do Agar Muller Hinton o pH deveria situar-se entre 7,2 e 7,4. Antes do uso a placa e os frascos contendo os discos de antibióticos foram mantidos em temperatura ambiente por 20 até o máximo de 30 minutos sendo a colocação dos discos de antibióticos nas placas realizadas em, no máximo, 15 minutos após a semeadura. Foram utilizados no máximo cinco discos por placa de $100 \mathrm{~mm}$, e a temperatura de incubação da placa teste utilizada foi $35^{\circ} \mathrm{C}$. A leitura do teste foi realizada entre 18 e 24 horas após a incubação. A identificação dos microorganismos foi realizada segundo as características culturais, morfológicas, tintoriais e bioquímicas (Carter 1988). Após a identificação, as amostras foram testadas quanto à susceptibilidade a antibióticos por difusão em disco de ágar in vitro (Bauer et al. 1966) utilizando-se discos de antibióticos segundo indicações terapêuticas para cada sítio de infecção, ou de acordo com o tratamento adotado na rotina, sendo que 59 pacientes já estavam sendo medicados com antibióticos sem sucesso, principalmente nos casos de cistite e feridas, justificando a escolha dos antibióticos em diferentes frequências.

Os antibióticos testados foram amicacina $30 \mathrm{mcg}^{5}$, amoxacilina associada ao ácido clavulânico $30 \mathrm{mcg}^{5}$, amoxacilina $10 \mathrm{mcg}^{5}$, ampicilina $10 \mathrm{mcg}^{5}$, cefalotina $30 \mathrm{mcg}^{5}$, cefalexina $30 \mathrm{mcg}^{5}$, ceftiofur $30 \mathrm{mcg}^{5}$, clindamicina $2 \mathrm{mcg}^{5}$, ciprofloxacina $5 \mathrm{mcg}^{5}$, enrofloxacina $5 \mathrm{mcg}^{5}$, gentamicina $10 \mathrm{mcg}^{5}$, lincomicina $5 \mathrm{mcg}^{6}$, neomicina $30 \mathrm{mcg}^{5}$, norfloxacina $10 \mathrm{mcg}^{5}$, orbifloxacina $10 \mathrm{mcg}^{7}$, penicilina $5 \mathrm{mcg}^{5}$, sulfazotrin $25 \mathrm{mcg}^{5}$ e tobramicina $10 \mathrm{mcg}^{5}$. As zonas de inibição dos antibióticos foram interpretados de acordo com Clinical and Laboratory Standards Institute (CLSI 2008), com exceção do antibiótico Orbifloxacina para o qual se seguiu a indicação do fornecedor.

\section{RESULTADOS}

Dos 181 casos estudados, 48,1\% (87/181) foram isolados de feridas, $30,4 \%(55 / 181)$ de afecções do trato urinário, $17,1 \%$ (31/181) de afecções otológicas, 2,8\% (5/181) de afecções ortopédicas e 1,7\% (3/181) de peritonites. Dentre as feridas, 79 amostras foram isoladas de cães e oito de gatos. Nas infecções do trato urinário 29 amostras foram isoladas de cães e 26 de gatos. As demais amostras foram isoladas apenas de cães. Dentre os 59 pacientes que já estavam sendo medicados com antibióticos, $33(18,2 \%)$ recebiam cefalosporinas, $14(7,7 \%)$ enrofloxacina, três $(1,7 \%)$ amoxicilina e nove (5\%) outros antibióticos como amoxicilina + ácido clavulânico, sulfametoxazol + trimetoprima, ampicilina, gentamicina, espiramicina + metronidazol e neomicina, este último na forma tópica, em dois casos de otite.

Os agentes bacterianos encontrados com maior frequência foram Staphylococcus spp e Pseudomonas spp (Quadro 1) que estavam presentes principalmente nas feridas. Nas feridas e afecções do trato urinário, a maior parte das infec-

\footnotetext{
${ }^{4}$ HiMedia, Laboratories, Mumbai, Índia.

5 Laborclin, Casimiro de Abreu 521, Curitiba, PR.

${ }^{6}$ NEWPROV, ${ }^{\circ}{ }^{\circ}$ de maio 590, Curitiba, PR.

7 Schering Plough, Antônio das Chagas 1623, Chácara Santo Antônio, São Paulo, SP.
} 


\section{Quadro 1. Distribuição em frequência e porcentagem dos agentes bacterianos em animais atendidos no Setor de Clínica Cirúrgica de Animais de Companhia do HV/ UEL entre janeiro de 2008 e dezembro de 2009}

\begin{tabular}{l} 
Agente \\
\hline Staphylococcus spp. \\
Pseudomonas spp. \\
Escherichia coli \\
Streptococcus spp. \\
Proteus spp. \\
Enterobater spp. \\
Enterococcus spp. \\
Klebsiella spp. \\
Serratia spp. \\
Corynebacterium spp. \\
Bactérias Corineformes \\
Acinetobacter spp. \\
Yersinia spp. \\
Hafnia alvei \\
Total
\end{tabular}

de antibióticos, os aminoglicosídeos e as quinolonas. As bactérias Gram positivas apresentaram maior resistência à clindamicina, ciprofloxacina e à neomicina e maior sensibilidade à tetraciclina, norfloxacina e gentamicina.

Nas peritonites, os isolados apresentaram resistência à amicacina, amoxacilina associada ao ácido clavulânico, ampicilina, cefalotina, cefalexina, ceftiofur, clindamicina, ciprofloxacina, doxiciclina, enrofloxacina, gentamicina, neomicina, norfloxacina, penicilina e sulfazotrin.

As bactérias Gram positivas isoladas dos casos ortopédicos apresentaram resistência à ciprofloxacina e à gentamicina em três e quatro amostras respectivamente, e sensibilidade à amoxacilina associada ao ácido clavulânico e à cefalexina em três e quatro amostras respectivamente. Pseudomonas spp, isolada em apenas um caso, apresentou resistência à amoxacilina associada ao ácido clavulânico, ampicilina, cefalexina e sulfazotrin, e sensibilidade à amicacina, enrofloxacina e gentamicina.

Quadro 2. Frequência de bactérias Gram negativas e Gram positivas detectadas em cães e gatos entre janeiro de 2008 e dezembro de 2009

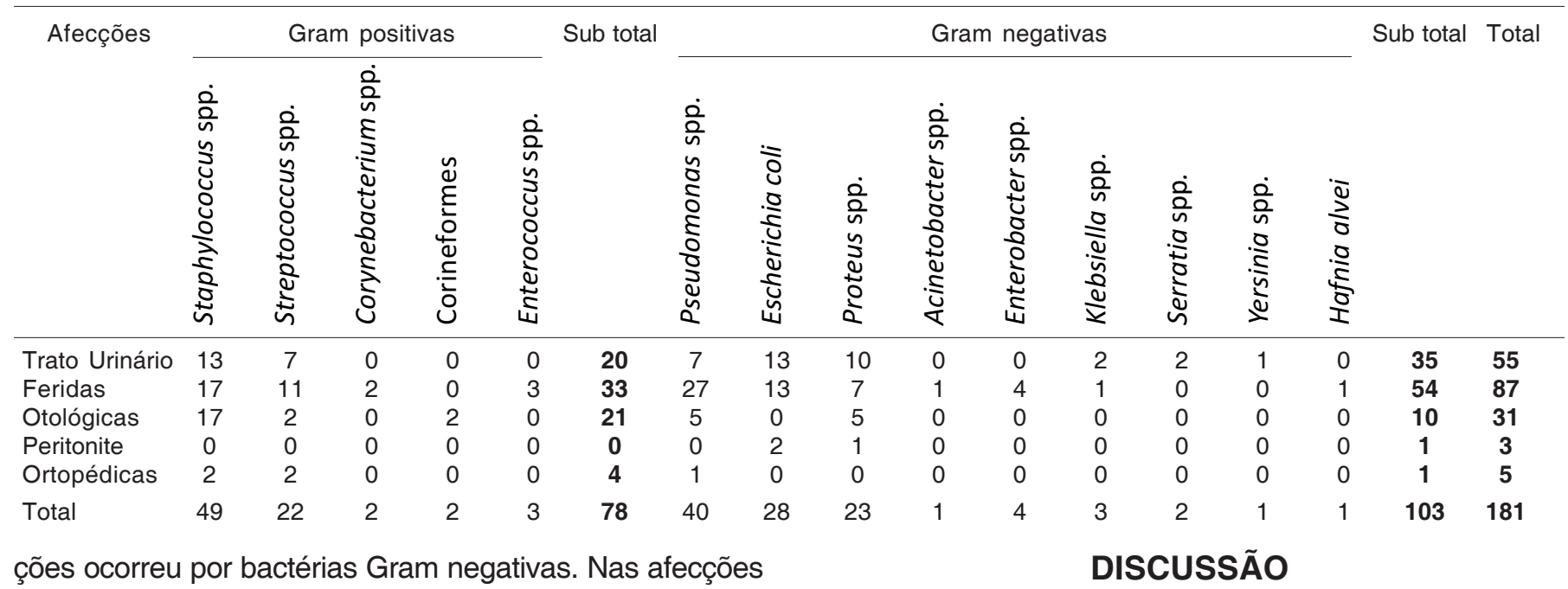
otológicas e ortopédicas prevaleceram as Gram positivas. Não houve presença de bactérias Gram positivas nos casos de peritonite (Quadro 2).

Notou-se alta porcentagem de resistência aos antibióticos testados in vitro nas afecções do trato urinário, principalmente das bactérias Gram negativas. Com exceção da norfloxacina, as Gram negativas apresentaram resistência maior que $67 \%$ aos demais antibióticos (Quadro 3 ).

Nas bactérias isoladas de feridas observou-se maior índice de resistência à cefalotina, cefalexina e clindamicina. Com exceção da amicacina, ciprofloxacina e gentamicina, as bactérias Gram negativas apresentaram resistência superior a $58 \%$ aos demais antibióticos testados, enquanto que nas Gram positivas a resistência foi menor.

Houve alta porcentagem de resistência bacteriana à neomicina $(65,4 \%)$ nas afecções otológicas. Quatro amostras de Staphylococcus spp. isoladas das afecções otológicas apresentaram resistência à cefalexina, sendo que duas dessas amostras apresentaram também resistência a duas classes

Os patógenos mais comumente isolados nas feridas foram Staphylococcus spp. e Pseudomonas spp. Meyers et al. (2007), que estudaram feridas decorrentes de mordeduras em cães, encontraram predominância de Pasteurella canis, Streptococcus canis e Staphylococcus intermedius. No mesmo estudo foi relatada uma alta suscetibilidade in vitroà sulfonamidas potencializadas de primeira e terceira geração, amoxacilina associada ao ácido clavulânico e às cefalexinas, contrastando com os resultados do presente trabalho, no qual foi encontrado alta resistência a estes antibióticos.

Mouro et al. (2010), em culturas de feridas por mordeduras em cães, observaram predominância de Pasteurella multocida e Sthaphylococcus intermedius. No mesmo estudo constatou-se alta suscetibilidade à amoxacilina associada ao ácido clavulânico sugerida como droga de primeira escolha em casos de mordeduras por cães, resultado que difere do atual trabalho, pois foram isoladas bactérias diferentes e com alta resistência a este antibiótico.

Arias et al. (2008), em estudo realizado no mesmo local do 
Quadro 3. Número total de amostras (N) em cada afecção e número de amostras resistentes (n) a antibióticos em bactérias Gram positivas e Gram negativas isoladas do trato urinário, de feridas e de otites de animais atendidos no Setor de Clínica Cirúrgica de Animais de Companhia do HV/UEL entre janeiro de 2008 e dezembro de 2009

\begin{tabular}{|c|c|c|c|c|c|c|c|c|}
\hline \multirow{2}{*}{$\begin{array}{c}\text { Antibió- } \\
\text { tico }^{a}\end{array}$} & \multicolumn{2}{|c|}{ Urinário } & \multicolumn{2}{|c|}{ Feridas } & \multicolumn{2}{|c|}{ Otites } & \multirow{2}{*}{$\begin{array}{c}\text { Total } \\
\text { Amos- } \\
\text { tras }\end{array}$} & \multirow{2}{*}{$\begin{array}{l}\% \\
\text { Re- } \\
\text { sist. }\end{array}$} \\
\hline & $\mathrm{G}+$ & G- & $\mathrm{G}+$ & G- & $\mathrm{G}+$ & G- & & \\
\hline & $N(n)$ & $N(n)$ & $N(n)$ & $N(n)$ & $N(n)$ & $N(n)$ & & \\
\hline AK & - & - & $18(8)$ & $31(8)$ & - & - & 49 & $32, €$ \\
\hline AMC & $4(1)$ & $9(8)$ & $2(0)$ & $10(8)$ & 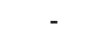 & - & 25 & 68,0 \\
\hline AM & $14(3)$ & $12(10)$ & $18(6)$ & 31 (29) & - & - & 75 & 64,0 \\
\hline AMP & $12(6)$ & $10(8)$ & - & 年 & - & - & 22 & 63,6 \\
\hline & $10(2)$ & $9(7)$ & $2(2)$ & $5(5)$ & - & - & 26 & 61 \\
\hline & $6(2)$ & $8(7)$ & 18 (11) & $27(26)$ & $11(4)$ & $9(9)$ & 79 & 74,7 \\
\hline $\mathrm{CT}$ & $2(2$ & 5 & 1. & $5(4)$ & ${ }^{\prime}$ & - & 12 & 91,6 \\
\hline C & - & $4(4)$ & $13(8)$ & $28(27)$ & $5(2)$ & $1(1)$ & 51 & 82,3 \\
\hline CIP & 4 (1) & $10(7)$ & 16 (11) & 31 (10) & $13(6)$ & $10(1)$ & 84 & 42,8 \\
\hline ENR & $17(9)$ & 18 (12) & 20 (13) & $34(20)$ & $19(6)$ & $9(3)$ & 117 & 53,8 \\
\hline & $2(0)$ & $9(7)$ & $4(1)$ & $8(3)$ & $8(2)$ & $10(2)$ & 41 & 36 , \\
\hline & & 1.1 & 1.1 & - & 18 (12) & $8(5)$ & 26 & 65 , \\
\hline & $16(9)$ & 15 & $4(2)$ & $8(5)$ & $11(2)$ & $9(2)$ & 63 & 41,3 \\
\hline OP & $3(3)$ & 3 (3) & - & - & - & - & 6 & 100 \\
\hline SU & 16 (11) & $18(14)$ & 17 (13) & 27 (21) & 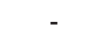 & - & 78 & 75, \\
\hline TOB & & & & & $19(6)$ & $8(3)$ & 27 & 33 \\
\hline
\end{tabular}

aAK: Amicacina; AMC: Amox.+ Ac. Clav.; AM: Amoxacilina; AMP: Ampicilina; KF: Cefalotina; CL: Cefalexina; CTF: Ceftiofur; CLI: Clindamicina; CIP: Ciprofloxacina; ENR: Enrofloxacina; GN: Gentamicina; NEO: Neomicina; NOR: Norfloxacina; ORB: Orbifloxacina; SUT: Sulfazotrin:; TOB: Tobramicina.

presente trabalho em 18 animais (17 cães e um gato) com feridas contaminadas e infectadas entre setembro de $2006 \mathrm{e}$ abril de 2007 , constataram que a as bactérias mais frequentes foram Pseudomonas spp. (30\%), Proteus (20\%), Staphylococcus spp. (15\%) e Streptococcus spp. (15\%), sendo que os resultados dos antibiogramas, quando comparados ao estudo atual, revelaram a diminuição da resistência das bactérias Gram negativas à amicacina, à amoxacilina associada ao ácido clavulânico, à ciprofloxacina e à gentamicina, enquanto que a sensibilidade à norfloxacina, a cefalosporinas e ao sulfazotrin praticamente não mudou neste período. Com relação às Gram positivas, houve diminuição da resistência à amicacina e à ciprofloxacina e aumento da resistência à cefalexina, enquanto que a sensibilidade à enrofloxacina não se alterou neste período. Esta alteração dos padrões de resistência provavelmente é consequência das mudanças instituídas na terapêutica dos pacientes atendidos neste setor, pois os antibióticos passaram a ser utilizados com maior critério e com base na realização de cultura e antibiograma, com exceção das cefalosporinas, principalmente a cefalotina injetável, que ainda é bastante usada na rotina, no início do atendimento de pacientes com feridas traumáticas.

A predominância de Escherichia coli, Proteus spp. e Staphylococcus spp. em infecções do trato urinário (ITU) também foi obtida por Cohn et al. (2003), que ao estudarem a tendência do desenvolvimento de resistência às fluorquinolonas em 1478 isolados bacterianos do trato urinário de cães, entre janeiro de 1998 a dezembro de 2001, detectaram um aumento da resistência ao longo dos anos, porém esses antibióticos ainda foram considerados eficazes em mais de $80 \%$ dos isolados testados in vitro. Já no presente trabalho foi observada maior porcentagem de resistência às fluorquinolonas nas ITU, principalmente das bactérias Gram negativas. As quinolonas, principalmente a enrofloxacina, é um dos principais antibióticos usados na rotina deste hospital, e também é facilmente adquirida em farmácias veterinárias, sem receita, sendo que $7,73 \%$ dos pacientes, quando atendidos pela primeira vez já estavam sendo medicados com este antibiótico. Assim, o aumento da resistência às fluorquinolonas provavelmente tem relação com sua ampla utilização em medicina veterinária, devido à eficácia, relativa segurança (Cohn et al. 2003) e amplo espectro de ação (Pallo-Zimmerman et al. 2010). As bactérias Gram negativas são historicamente consideradas sensíveis às fluorquinolonas, mas a resistência a essa classe de antibióticos progrediu consideravelmente, ocorrendo por mutação, porém atualmente é também mediada por plasmídeos, o que se acreditava, não ocorria nesta classe de antibióticos (PalloZimmerman et al. 2010).

Perfil de resistência similar ao encontrado nas ITU na presente pesquisa também foi observado nos estudos de Cooke et al. (2002), que isolaram Escherichia coli em 56 amostras de cães com cistite e detectaram resistência à enrofloxacina e a antibióticos comumente usados no tratamento de ITU. Na presente pesquisa, as bactérias Gram negativas apresentaram alta resistência aos mesmos antibióticos.

No presente estudo, em $55 \%$ dos casos otológicos, Staphylococcus spp. foi o agente etiológico predominante; resultado superior ao encontrado por Tunon et al. (2008), que estudando estafilococos multirresistentes de otite em cães, detectaram este agente em $32,7 \%$ dos casos de otite canina. Esses autores verificaram alta suscetibilidade à cefalexina, gentamicina, norfloxacina e tetraciclina, resultados que também foram verificados nas culturas Gram positivas do presente trabalho. Verificou-se ainda alta resistência à neomicina, antibiótico usado comumente em preparações tópicas no tratamento de otites em cães e gatos, sendo que Tunon et al. (2008) também observaram alta sensibilidade ao mesmo antibiótico.

Lilenbaum et al. (2000), testaram a suscetibilidade de Staphylococcus spp. isolados de otites em cães e verificaram maior quantidade desse agente que a atual pesquisa $(67,7 \%)$, e constataram alta suscetibilidade à gentamicina e tetraciclina, mesmos resultados encontrados em isolados Gram positivos no presente estudo. Oliveira et al. (2005), estudando otite externa de cães, encontraram um perfil de resistência de Pseudomonas aeruginosa similar ao das bactérias Gram negativas deste estudo, verificando maior resistência à cefalexina, e à tetraciclina. Scartezzini et al. (2010) também verificaram em otites causadas por Pseudomonas spp. em cães, alta resistência à cefalexina e ao cloranfenicol, e baixa resistência à ciprofloxacina e à enrofloxacina.

Staphylococcus spp. sensíveis à penicilina são também suscetíveis a outras cefalosporinas, cefens e carbapenens. Por outro lado, o teste de resistência à cefoxitina, não testada no presente trabalho, deve ser realizada para prever a 
presença de resistência à oxacilina mediada pelo gene Meca (Guardabassi et al. 2008). No presente estudo a presença de quatro amostras resistentes à cefalexina e a outras classes de agentes antimicrobianos nos casos otológicos, principalmente às fluorquinolonas, é preocupante, pois poderia indicar a presença de Staphylococcus aureus ou de Staphylococcus intermmedius resistentes à meticilina (MRSA), consideradas um sério desafio terapêutico em veterinária em países da América do Norte e Europa (Guardabassi et al. 2008). O aumento do número das bactérias multirresistentes em animais e humanos mostra a necessidade de desenvolver e implementar medidas para monitorar e controlar a difusão de resistência (Umber \& Bender 2009).

Nos casos ortopédicos, os dois isolados de Staphylococcus spp. foram susceptíveis à gentamicina, enrofloxacina, clindamicina e cefalexina e os dois isolados de Streptococcus spp. foram sensíveis à amoxacilina associada ao ácido clavulânico, à cefalexina e à enrofloxacina. Simionato et al. (2003), que avaliaram processos de osteomielite canina, também verificaram baixa resistência de Staphylococcus spp. e Streptococcus spp. aos mesmos antibióticos, com exceção da enrofloxacina, à qual o Streptococcus spp apresentou $50 \%$ de resistência. O mesmo estudo observou a susceptibilidade de Pseudomonas spp. à gentamicina, resultado também verificado na presente pesquisa.

Apesar de Guardabassi et al. (2008) recomendarem a utilização de amicacina, gentamicina, penicilina ou clindamicina de forma empírica no tratamento de peritonites, a presente pesquisa verificou resistência a esses antibióticos nos casos dessa afecção, demonstrando que a terapêutica antimicrobiana não deve ser instituída sem o apoio de exames de cultura e antibiograma.

Os resultados do presente trabalho demonstraram a necessidade do monitoramento constante do perfil de resistência bacteriana, que varia ao longo dos anos e difere de local para local. A realização de testes para identificação bacteriana e sua sensibilidade para auxiliar na seleção apropriada do agente antimicrobiano se mostrou essencial devido a altas taxas de resistência bacteriana verificadas nesta pesquisa. Esses exames não devem ser negligenciados, pois favorecem a escolha prudente da antibioticoterapia adotada, reduzem o uso de antibióticos e consequentemente o desenvolvimento de resistência bacteriana.

Agradecimentos.- Ao técnico de Laboratório, José Aldevino de CarvaIho, e à Técnica de Nível Superior Med. Vet. M.S. Lucienne Garcia Pretto Giordano, pela paciência, auxílio, realização das culturas e antibiogramas, e aos residentes do HV/UEI, por participarem na colheita dos materiais analisados.

\section{REFERÊNCIAS}

Arias M.V.B., Batagllia L.A., Aiello G., Carvalho T.T. \& Freitas J.C. 2008. Identificação da suscetibilidade antimicrobiana de bactérias isoladas de cães e gatos com feridas traumáticas contaminadas e infectadas. Semina 29:861-874.

Bauer A.W., Kirby W.M.M., Sherris J.C. \& Turck M. 1966. Antibiotic susceptibility testing by a standardized single disk method. Am. J. Clin. Pathol. 45:493-496.
Carter G.R. 1988. Fundamentos de Bacteriologia e Microbiologia Veterinária. $3^{\text {a }}$ ed. Roca, São Paulo. 249p.

Clarke C.R. 2006. Antimicrobial resistance. Vet. Clin. North Am., Small Anim. Pract. 36:987-1001.

CLSI 2008. Performance standards for antimicrobial disk and dilution susceptibility tests for bacteria isolated from animals. $3^{\text {rd }}$ ed. Approved standard M31-A3, Clinical and Laboratory Standards Institute, Wayne, PA

Cohn L.A., Gary A.T., Fales W.H. \& Madsen R.W. 2003. Trends in fluoroquinolone resistance of bacteria isolated from canine urinary tracts. J. Vet. Diagn. Invest. 15:338-343.

Cooke C.L., Singer R.S., Jang S.S. \& Hirsh D.C. 2002. Enrofloxacin resistance in Escherichia coli isolated from dogs with urinary tract infections. J. Am. Vet. Med. Assoc. 220:1139-1141.

Guardabassi L., Houser G.A., Frank L.A. \& Papich M.G. 2008. Orientações para o uso de antimicrobianos em cães e gatos, p.224-249. In: Guardabassi L., Jesen L.B. \& Kruse H. (Eds), Guia de Antimicrobianos em Veterinária. Artmed, Porto Alegre.

Guardabassi L., Schwarz S. \& Lloyd D. 2004. Pet animals as reservoirs of antimicrobial-resistant bacteria. J. Antimicrob. Chemother. 54:321332.

Hoekstra K.A. \& Paultron R.J.L. 2002. Clinical prevalence and antimicrobial susceptibility of Staphylococcus aureus and Staphylococcus intermedius in dogs. J. Appl. Microbiol. 93:406-413.

Lilenbaum W., Veras M., Blum E. \& Souza G.N. 2000. Antimicrobial susceptibility of staphylococci isolated from otitis externa in dogs. Lett. Appl. Microbiol. 31:42-45.

Mendes C., Oplustil C., Sakagami E., Turner P. \& Kiffer C. 2005. Antimicrobial susceptibility in Intensive Care Units: MYSTIC Program Brazil 2002. Braz. J. Infect. Dis. 9(1):44-51.

Meyers B., Schoeman J.P., Goddard A. \& Picard J. 2007. The bacteriology and antimicrobial susceptibility of infected and non-infected dog bite wounds: Fifty cases. Vet. Microbiol. 127:360-368

Mouro S., Vilela C.L. \& Niza M.M.R.E. 2010. Clinical and bacteriological assessment of dog-to-dog bite wounds. Vet. Microbiol. 144:127-132

Oliveira L.C., Medeiros C.M.O., Silva I.N.G., Monteiro A.J., Leite C.A.L. \& Carvalho C.B.M. 2005. Susceptibilidade a antimicrobianos de bactérias isoladas de otite externa em cães. Arq. Bras. Med. Vet. Zootec. 57:405-408.

Pallo-Zimmerman L.M., Byron J.K. \& Graves T.K. 2010. Fluoroquinolonas: Then and now. Comp. Cont. Educ. Pract. Vet. 32:E1-E8.

Pedersen K., Pedersen K., Jensen H., Finster K., Jensen V.F. \& Heuer O.E. 2007. Occurrence of antimicrobial resistance in bacteria from diagnostic sample from dogs. J. Antimicrob. Chemoth. 60:775-781.

Sanchez S., Stevenson M.A.M., Hudson C.R., Maier M., Buffington T., Dam Q. \& Maurer M.M. 2002. Characterization of multidrug- resistant Escherichia coli isolates associated with nasocomial infections in dogs. J. Clin. Microbiol. 40:3586-3595.

Scartezzini M., Fischer C.D.B., Pianta C. \& Oliveira S.J. 2010. Otite causada por Pseudomonas sp. em cães atendidos no HV-ULBRA no ano 2009 (Canoas, RS). Anais 3o Anclivepa, Belém, PA. (Resumo)

Simionato A.C., Ramos M.C.C. \& Coutinho S.D.A. 2003. Isolamento de bactérias aeróbias e sua sensibilidade a antimicrobianos em processos de osteomielite canina. Arq. Bras. Med. Vet. Zootec. 55:148-154.

Tunon G.I.L., Silva E.P. \& Faierstein C.C. 2008. Isolamento de estafilococos multirresistentes de otites em cães e sua importância para saúde publica. Bepa 5:4-7.

Umber J.K. \& Bender J.B. 2009. Pets and antimicrobial resistance. Vet. Clin. North Am., Small Anim. Pract. 39:279-292.

Werckenthin C., Cardoso M., Martel J.L. \& Schwarz S. 2001. Antimicrobial resistance in Staphylococci from animal with particular reference to bovine Staphylococcus aureus, porcine Staphylococcus hyicus, and canine Staphylococcus intermedius. Vet. Res. 32:341-362.

Witte W. 1999 Antibiotic resistance in gram-positive bacteria: Epidemiological aspects. J. Antimicrob. Chemoth. 44 (Suppl.A):1-9. 